\title{
NMDA Receptor-Dependent Long-Term Potentiation and Long-Term Depression (LTP/LTD)
}

\author{
Christian Lüscher ${ }^{1}$ and Robert C. Malenka ${ }^{2}$ \\ ${ }^{1}$ Department of Basic Neurosciences and Clinic of Neurology, University of Geneva and Geneva University \\ Hospital, 1211 Geneva, Switzerland \\ ${ }^{2}$ Nancy Pritzker Laboratory, Department of Psychiatry and Behavioral Sciences, Stanford University School of \\ Medicine, Palo Alto, California 94305-5453 \\ Correspondence: Christian.Luscher@unige.ch and malenka@stanford.edu
}

Long-term potentiation and long-term depression (LTP/LTD) can be elicited by activating $\mathrm{N}$-methyl-D-aspartate (NMDA)-type glutamate receptors, typically by the coincident activity of pre- and postsynaptic neurons. The early phases of expression are mediated by a redistribution of AMPA-type glutamate receptors: More receptors are added to potentiate the synapse or receptors are removed to weaken synapses. With time, structural changes become apparent, which in general require the synthesis of new proteins. The investigation of the molecular and cellular mechanisms underlying these forms of synaptic plasticity has received much attention, because NMDA receptor-dependent LTP and LTD may constitute cellular substrates of learning and memory.

L ong-term synaptic plasticity is a generic term that applies to a long-lasting experience-dependent change in the efficacy of synaptic transmission. Here we will focus on $N$-methyl-D-aspartate (NMDA) receptor-dependent synaptic potentiation (LTP) and depression (LTD), two forms of activity-dependent long-term changes in synaptic efficacy that have been extensively studied. Because both LTP and LTD are believed to represent cellular correlates of learning and memory, they have attracted considerable interest. In this article we will focus on the molecular and cellular mechanisms associated with LTP and LTD. As for other forms of long-term synaptic plasticity, a characterization of LTP and LTD involves describing the molecular mechanisms that are required to elicit the change (in- duction), followed by an investigation of the mechanism of expression (hours) and maintenance (days). The best-characterized form of NMDA receptor (NMDAR)-dependent LTP occurs between CA3 and CA1 pyramidal neurons of the hippocampus (Fig. 1). Throughout the chapter we will mostly refer to this specific form of LTP. At these CA3-CA1 Schaffer collateral synapses, the loci of both induction and expression are situated in the postsynaptic neuron.

\section{AMPA-TYPE AND NMDA-TYPE GLUTAMATE RECEPTORS}

After exocytotic release of the content of the synaptic vesicle from the presynaptic specialization (see Castillo 2012), the neurotransmitter

Editors: Morgan Sheng, Bernardo Sabatini, and Thomas C. Südhof

Additional Perspectives on The Synapse available at www.cshperspectives.org

Copyright (C) 2012 Cold Spring Harbor Laboratory Press; all rights reserved; doi: 10.1101/cshperspect.a005710

Cite this article as Cold Spring Harb Perspect Biol 2012;4:a005710 
A
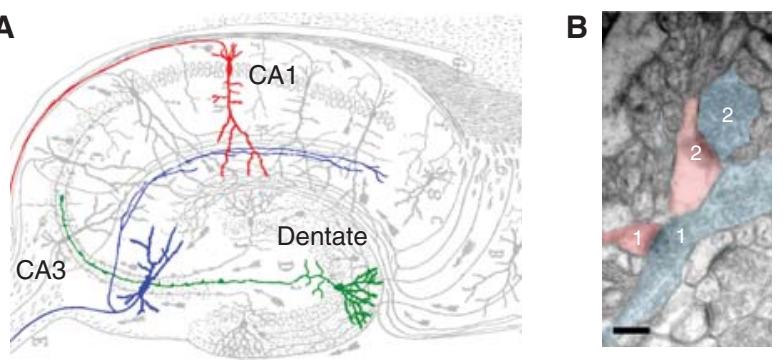

C

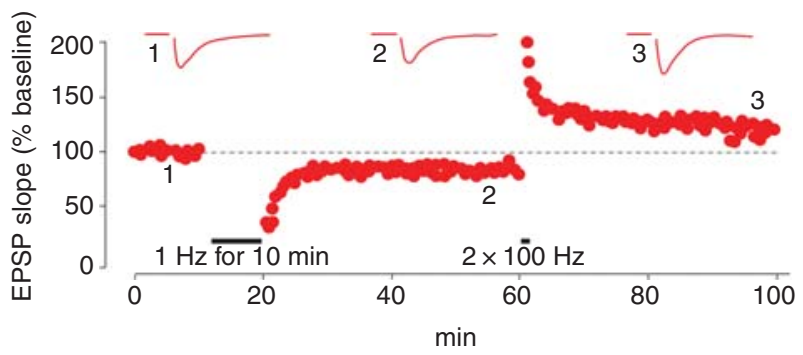

Figure 1. NMDAR-dependent LTD and LTP in the hippocampus. (A) Historical drawing by Ramon y Cajal (1909) of the trisynaptic pathway in the hippocampus. LTP and LTD are induced by activation of NMDARs at synapses between CA3 and CA1 pyramidal neurons (blue and red). In contrast, LTP at mossy fiber synapses onto CA3 neurons (green on blue) is NMDAR-independent. (B) This electron microscopy image shows the densely packed neuropil in the CA1 region of the hippocampus and highlights two asymmetric CA3-CA1 synapses. Note the typical "bouton en passant" configuration of synapse 1 and the prominent spine in synapse 2 . The postsynaptic densities (PSDs) are visible. Scale bar, $200 \mathrm{~nm}$. (Image kindly provided by Rafael Luján, Universitad de Castilla-La Mancha.) (C) Bidirectional change in CA3-CA1 synaptic efficacy by LTD and LTP in the same synapses monitored by extracellular field recordings in an acute slice preparation of the hippocampus. Note the contrasting induction protocols (Data from C Lüscher, unpubl.).

rapidly diffuses across the synaptic cleft and reaches the postsynaptic membrane, where it binds to its respective receptors. The neurotransmitter concentration in the synaptic cleft remains high for only a very brief period. Ionotropic receptors are direct ligand-gated ion channels that respond rapidly to the brief pulse of neurotransmitter released from the synaptic vesicle. The evoked synaptic currents are typically believed to last only a few milliseconds. The most common excitatory transmitter is glutamate, whereas many inhibitory synapses use $\gamma$-aminobutyric acid (GABA) for transmission.

Here we will first discuss the ionotropic members that are directly involved in synaptic plasticity of excitatory transmission, NMDA and AMPA-type glutamate receptors (NMDARs, AMPARs) (Dingledine et al. 1999). Both are ionotropic receptors that are permeable to $\mathrm{Na}^{+}$and
$\mathrm{K}^{+}$. Activation of ionotropic glutamate receptors leads to strong influx of $\mathrm{Na}^{+}$and only a small efflux of $\mathrm{K}^{+}$, such that the net effect is the depolarization of the postsynaptic neuron.

The workhorse of glutamatergic transmission is the AMPAR, which drives large and rapid synaptic signaling (Fig. 2). There are four genes encoding AMPARs (GRIA1 to -4). Each AMPAR is composed of four subunits, which can be a homomeric or heteromeric mixture of GluA1 to -4. Most AMPARs contain at least one subunit of GluA2. Following transcription this subunit undergoes RNA editing, whereby the RNA coding for a glutamine residue in the ion channel pore-forming region is exchanged for the RNA codon for arginine. This process is an essential step in the quality control. Nonedited GluA2 will be retained in the endoplasmic reticulum. The large arginine residue located in 


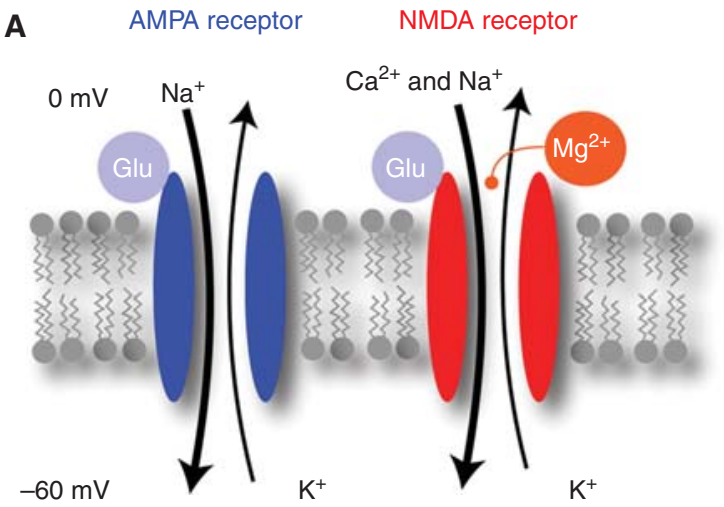

B

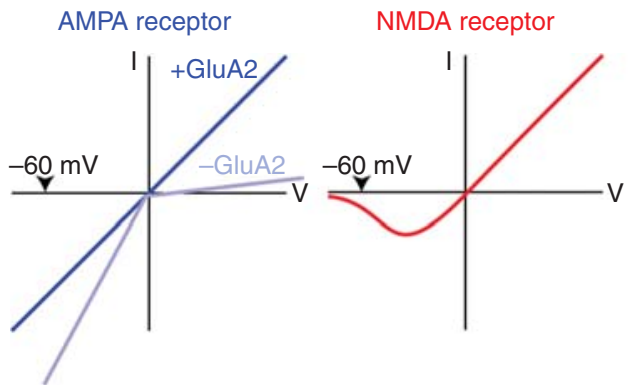

Figure 2. Major ionotropic glutamate receptors involved in LTD and LTP. (A) When glutamate binds to AMPA receptors, many sodium ions flow into the cell while only some potassium ions leave the neuron, causing a net depolarization of the membrane. NMDA receptors are also permeable for calcium but only if the magnesium is expelled by a slight depolarization of the neuron. (B) The current-voltage $(I-V)$ relationship provides a biophysical signature for the different receptors. AMPA receptors have a linear $I-V$ relationship when they contain the subunit GluA2, but are inward-rectifying (see text for definition) without GluA2. NMDA receptors have a complex $I-V$ curve because $\mathrm{Mg}$ blocks the pore at negative potentials.

the pore region of the channel limits the flow of $\mathrm{Na}^{+}$and $\mathrm{K}^{+}$ions and prevents divalent ions from entering the cell. This design renders AMPARs that contain GluA2 calcium-impermeable (Liu and Zukin 2007).

AMPARs carry inward currents at negative potentials and outward currents at positive potentials, and the reversal potential is $0 \mathrm{mV}$. For receptors that contain GluA2, this relationship is symmetrical, i.e., the current-voltage relationship is linear. In contrast, for receptors that lack GluA2 (e.g., GluA1 homomeric or GluA1/3 heteromeric channels), the currentvoltage relationship shows an interesting nonlinear voltage-dependent interaction. GluA2lacking AMPARs have a glutamine residue in the pore region instead of the arginine in the
GluA2. Such channels have a high conductance for sodium and are even permeable for calcium. Because endogenous polyamines, which are negatively charged, can also access a site close to the cytoplasmic mouth of the pore, the channels are inhibited at positive potentials. As a consequence, GluA2-lacking AMPARs have an inward-rectifying current-voltage relationship (i.e., they conduct current more easily into the cell than out of the cell; Fig. 2). Such calcium-permeable AMPARs are expressed on many GABAergic neurons.

The current-voltage relationship of NMDARs is even more complex. At negative membrane potentials close to the resting membrane potential, magnesium ions enter the pore of the NMDAR, blocking the passage for all other 
ions. Upon depolarization the magnesium is expelled from the pore, allowing sodium, potassium, and, importantly, calcium ions to pass. At positive potentials NMDARs then show maximal permeability (i.e., large outward currents can be observed under these circumstances; Fig. 2). NMDARs also have much slower kinetics than AMPARs. Following release of glutamate, NMDARs activate more slowly, having a peak conductance long after the AMPAR peak conductance. NMDARs can also remain open for hundreds of milliseconds after presynaptic release of glutamate, much longer than the AMPARs, which typically open for only a few milliseconds. It is important to note that NMDARs conduct currents only when glutamate is bound and the postsynaptic neuron is depolarized. In other words, both the pre- and postsynaptic neurons need to be active to open NMDARs. Through this mechanism NMDARs play the role of molecular coincidence detectors, which, as we will see below, is essential for several forms of synaptic plasticity.

Ionotropic glutamate receptors do not work in isolation. They interact with many proteins of the postsynaptic density (PSD) (Elias and Nicoll 2007). Some of these proteins modulate glutamate receptor function, whereas others control their membrane insertion and removal. The number of glutamate receptors at a synapse (normally only a few dozens of receptors) can therefore be regulated through these interactions. A particularly important interacting protein is stargazin, as well as other members of the transmembrane AMPAR regulatory protein (TARP) family. Stargazin is in fact an auxiliary subunit of most AMPARs that affects conductance, kinetics, and rectification. In other words, in the physiological situation in which TARPs are present, the kinetics and pharmacology of neuronal AMPARs differ from those predicted by classical in vitro expression studies of AMPARs. PICK1 is another example of a protein that regulates the number of receptors at the synapse. Unlike the TARPs, which have little subunit specificity, PICK1 is believed to interact primarily with GluA2. Interfering with PICK1 and other interacting proteins has shown that synaptic AMPARs dynamically recycle within tens of minutes using mechanisms that allow rapid removal from and insertion into the PSD. Although under baseline conditions the number of receptors remains stable, rapid redistribution leading to a change in the number of synaptic receptors is a widely used mechanism for synaptic plasticity (see below).

Although the major role of ionotropic glutamate receptors is postsynaptic, they have also been found on presynaptic boutons, where they may participate in the regulation of transmitter release. Such presynaptic receptors can be activated by strong release from the bouton on which they are located (homosynaptic modulation) or by glutamate released by neighboring synapses (heterosynaptic modulation). Whether this activation enhances or inhibits further release varies from synapse to synapse.

\section{INDUCTION OF LTP AND LTD}

LTP and LTD are induced by specific patterns of activity (Malenka 1994). For LTP induction both pre- and postsynaptic neurons need to be active at the same time because the postsynaptic neuron must be depolarized when glutamate is released from the presynaptic bouton to fully relieve the $\mathrm{Mg}^{2+}$ block of NMDARs. As a consequence of coincident depolarization and glutamate binding, calcium influx through NMDARs is maximal, which activates intracellular signaling cascades that ultimately are responsible for the altered synaptic efficacy. NMDAR-dependent LTP is therefore an associative form of plasticity and fulfills the criteria for correlated activity as the origin of the strengthening of the connection between two neurons proposed by Donald Hebb more than 60 years ago (Hebb 1949). Conversely, LTD can be induced by repeated activation of the presynaptic neuron at low frequencies without postsynaptic activity (see below). Because the driving force for calcium entry is very large for a neuron at rest and the block of NMDARs by $\mathrm{Mg}^{2+}$ is incomplete even at resting potentials (Jahr and Stevens 1993), significant Ca enters the cell in response to synaptic stimulation (Sabatini et al. 2002; Bloodgood and Sabatini 2007; Bloodgood et al. 2009) during low-frequency synaptic 
stimulation. Presumably it is repeated occurrence of this smaller NMDAR-dependent Ca influx that triggers LTD induction.

Because NMDAR-dependent calcium influx induces both LTP and LTD, the cell must have a way to decide whether to potentiate or depress a synaptic connection. An early model invoked the level of activity or depolarization in the postsynaptic cell as the critical variable dictating whether LTP or LTD was evoked (or no change in synaptic strength). Indeed, it is now fairly well accepted that modest activation of NMDARs leading to modest increases in postsynaptic calcium are optimal for triggering LTD, whereas much stronger activation of NMDARs leading to much larger increases in postsynaptic calcium are required to trigger LTP (Malenka 1994).

An important property of these NMDARdependent forms of LTP and LTD is that they are input- or synapse-specific. That is, only synapses that actively contribute to the induction process will undergo the plasticity. This is because NMDARs on the synapses must be activated by synaptically released glutamate during the induction protocol. The synapse specificity of LTP has been explicitly tested using photolytic release of glutamate to bypass the presynaptic terminal and directly stimulate a visualized dendritic spine with glutamate. Experiments using this approach to induce NMDAR-dependent LTP have shown that LTP can be induced at a single synapse without causing postsynaptic potentiation or depression of neighboring synapses (Matsuzaki et al. 2004; Harvey and Svoboda 2007; but see Engert and Bonhoeffer 1997). However, interactions between neighboring synapses do occur, such that the intradendritic spread of the activated Ras from an active synapse briefly lowers the threshold for subsequent LTP induction at neighboring synapses (Harvey et al. 2008).

In acute slices of the hippocampus, LTP is often induced by tetanic stimulation of Schaffer collaterals. High-frequency stimulation protocols typically comprise delivery of one or several trains of pulses at $50-100 \mathrm{~Hz}$ for $1 \mathrm{sec}$. It may be surprising that stimulation of the presynaptic axons alone is sufficient for LTP induction.
However, this makes sense because high-frequency stimulation protocols cause a strong temporal summation of the excitatory postsynaptic potentials (EPSPs), and the resultant large depolarization of the postsynaptic cell is sufficient to relieve the $\mathrm{Mg}$ block of the NMDAR and allow a large amount of calcium to enter the postsynaptic cells during the induction protocol. In contrast, low-frequency stimulation of presynaptic axons is commonly used to induce LTD. Typically such protocols involve stimulation at $1-3 \mathrm{~Hz}$ for $5-15 \mathrm{~min}$. This causes only a modest amount of postsynaptic depolarization, resulting in a modest but prolonged increase in postsynaptic calcium due to modest and repetitive activation of NMDARs. A variant of these induction protocols is the so-called pairing protocol, whereby during low-frequency activation of axons $(0.1-1 \mathrm{~Hz})$, individual cells are held at depolarized membrane potentials by passing current through the recording electrode. This provides relief of the $\mathrm{Mg}$-dependent block of NMDARs, allowing calcium to enter the postsynaptic cell when the NMDARs are activated by the presynaptically released glutamate. Consistent with original ideas (Bienenstock et al. 1982), modest depolarization can elicit LTD, whereas stronger depolarization leads to LTP.

More recently studies have shown that LTP and LTD can be elicited if action potentials in the pre- and postsynaptic neurons coincide with the appropriate timing. From the perspective of the postsynaptic neuron (which is where the recordings are made), these manipulations lead to both a synaptic potential and an action potential that backpropagates into the dendrites, which presumably provides the additional depolarization required to facilitate calcium influx through the activated NMDARs (Stuart et al. 1997; Waters et al. 2005). If a presynaptic spike is repetitively elicited slightly before (e.g., $5 \mathrm{msec}$ ) the postsynaptic neuron is fired, the EPSP precedes the backpropagating action potential and such repetitive "pre-post" action potential firing can generate LTP. Conversely, when the backprogating action potential is repetitively elicited before the presynaptic spike, "post-pre" firing, LTD is often observed. The time window for such pairings is critical, 
such that the closer in time presynaptic and postsynaptic spikes are fired, the larger the magnitude of the plasticity induced. If both stimulations, however, occur at once, an asymptote is reached, in which the resultant long-term change in synaptic strength can no longer be reliably predicted. As the direction of synaptic plasticity depends on the timing between the presynaptic and postsynaptic spikes, this phenomenon has been named spike-timing-dependent plasticity (Dan and Poo 2006; Caporale and Dan 2008). It is often a considered a more physiological method of inducing LTP or LTD because it is imagined that these patterns of spiking may occur during real behavior.

\section{EXPRESSION MECHANISM}

During the last two decades of the last century, the locus of expression of NMDAR-dependent LTP was the focus of an intense debate (Malenka and Nicoll 1999; Nicoll 2003). Although in hindsight it seems difficult to understand how an apparently simple question could keep many researchers in the field busy, the confusion could largely be attributed to the lack of understanding of the basic physiology of excitatory synapses in the mammalian central nervous system. Although a minority of researchers in the field would argue that the question is still not fully answered, there is general agreement that the experiments that were performed to address this topic significantly furthered our understanding of the basic properties of synaptic transmission.

In theory, how LTP and LTD are expressed is a simple question. For LTP the increase in synaptic strength could be due either to more transmitter being released from the presynaptic axons being activated during the course of the experiment or to the same amount of transmitter being released but having a greater effect because the postsynaptic cell was more sensitive to the same amount of released neurotransmitter. It is important to note that if LTP (or LTD) is caused by enhanced (or decreased) transmitter release, it requires that the postsynaptic cell somehow communicate to the presynaptic terminals and modify their function. This is re- quired because it is well established that NMDAR-dependent LTP and LTD are triggered in the postsynaptic cell. Indeed, during the debate about the locus of expression for LTP (and LTD), there was much discussion about the possible identity of so-called retrograde messengers, the substances that might be released from postsynaptic cells following appropriate activation of NMDARs and modify presynaptic function (Arancio et al. 1996; but see Williams et al. 1993).

To solve the pre- versus post- debate, which primarily focused on the locus of expression of LTP, a large number of experiments were performed. To assess whether presynaptic function changed, the assays included:

- Using use-dependent open channel blockers of postsynaptic receptors to estimate the release probability. Most importantly, dizocilpine (MK-801) irreversibly blocks NMDARs once they are activated by glutamate. Thus, once glutamate is released from a single presynaptic terminal and activates its corresponding postsynaptic NMDARs, those NMDARs are irreversibly blocked. This means that application of MK-801 while activating a population of synapses leads to a gradual decrease of the postsynaptic currents generated by NMDARs, and the rate of this decrease directly correlates with the overall probability of release of the synapses being activated. Importantly, it was found that the rate of this decrease remains unaltered by LTP but is clearly affected by other manipulations that are known to influence the probability of transmitter release (Manabe and Nicoll 1994).

- Monitoring short-term plasticity before and after the induction of LTP. Paired-pulse ratios and short-term facilitation or depression of synaptic responses during short, high-frequency bursts of stimulation reflect shortterm changes in release probability. These ubiquitous forms of short-term synaptic plasticity are greatly influenced by the baseline release probability yet were unaffected by the generation of LTP (McNaughton 1982; 
Manabe et al. 1993; but see Schulz et al. 1995).

- Monitoring glial glutamate transporter currents before and after LTP. The reuptake of glutamate by astrocytes is electrogenic, and thus currents can be measured from astrocytes that reflect the amount of transmitter released. There is, however, no change in the size of these currents after induction of LTP even though other manipulations that affect transmitter release have clear effects. These experiments are particularly convincing, because this approach relies on a readout that is independent of glutamate receptors and therefore unlikely to participate in the expression of LTP (Diamond et al. 1998; Lüscher et al. 1998).

- Visualization of presynaptic exocytosis with styryl dyes such as FM1-43. These dyes stain presynaptic vesicles and are washed out once the vesicles fuse with the membrane in an activity-dependent fashion. Just as with MK801, the destaining curves were superimposable before and after tetanic induction of NMDAR-dependent LTP in CA1 neurons at 50-100 Hz (Zakharenko et al. 2001).

Taken together, these findings (and additional experiments that are not covered because of space limitations) make it very unlikely that LTP is associated with an increase in release probability or the amount of glutamate released from a presynaptic vesicle. But they say nothing about what postsynaptic mechanisms contribute to LTP (and LTD). An important clue to this question came from the observation that in the hippocampi of very young animals, some synapses contain only NMDARs and no, or very few, AMPARs. Thus, these synapses are functionally silent under baseline conditions. After the application of an LTP induction protocol, these synapses "wake up" and become functional because of the insertion of AMPARs into their postsynaptic membrane (Isaac et al. 1995; Liao et al. 1995). This result immediately raised the possibility that at both silent synapses and synapses that already contain AMPARs, LTP involves the insertion of more AMPARs into the synapse, whereas conversely, LTD may involve the removal or endocytosis of synaptic AMPARs (Fig. 3) (Lledo et al. 1998; Lüscher et al. 1999).

A large body of experimental evidence now supports this hypothesis (Lüscher et al. 2000; Lüscher and Frerking 2001; Malinow and Malenka 2002; Nicoll 2003; Collingridge et al. 2004; Malenka and Bear 2004). In fact, AMPARs can be quite mobile and recycle between the cytoplasm and the cell membrane even under baseline conditions within tens of minutes. This can be shown, for example, by interfering with endocytosis, which leads to a run-up of synaptic responses. It is presumably this mobile pool of AMPARs that allows for rapid but sustained changes in synaptic efficacy. The insertion and removal of AMPARs during LTP and LTD, respectively, is believed to involve classical mechanisms of SNARE protein-mediated exocytosis and dynamin-dependent endocytosis via clathrin-coated vesicles (Lüscher et al. 1999; Carroll et al. 2001; Kennedy and Ehlers 2011). Current evidence favors the idea that the endocytosis and exocytosis of AMPARs during LTD and LTP happens not directly at the synapse but at slightly perisynaptic locations, from where the receptors reach the postsynaptic density by lateral diffusion.

A large family of proteins associates with the AMPARs to regulate their mobility and biophysical properties as well as their stabilization within the PSD (see Sheng and Kim 2012). Different AMPAR subunits may play distinct roles in this redistribution process. Heteromeric GluA1/GluA2 receptors seem to be the primary subtype of AMPAR that is inserted into synapses during LTP (Adesnik and Nicoll 2007). In addition, there are also forms of synaptic potentiation that are expressed by an exchange of GluA2-containing AMPARs in the synapse for GluA2-lacking AMPARs (Liu and Zukin 2007). Because the latter have a higher conductance, this will potentiate the synapse even if the total number remains the same. It has also been suggested that during the very early phase of LTP (its first 10-20 $\mathrm{min}$ ), there is a transient appearance of GluA2-lacking AMPARs at the synapse and this is required for the maintenance of LTP (Plant et al. 2006). However, this finding 
C. Lüscher and R.C. Malenka

A

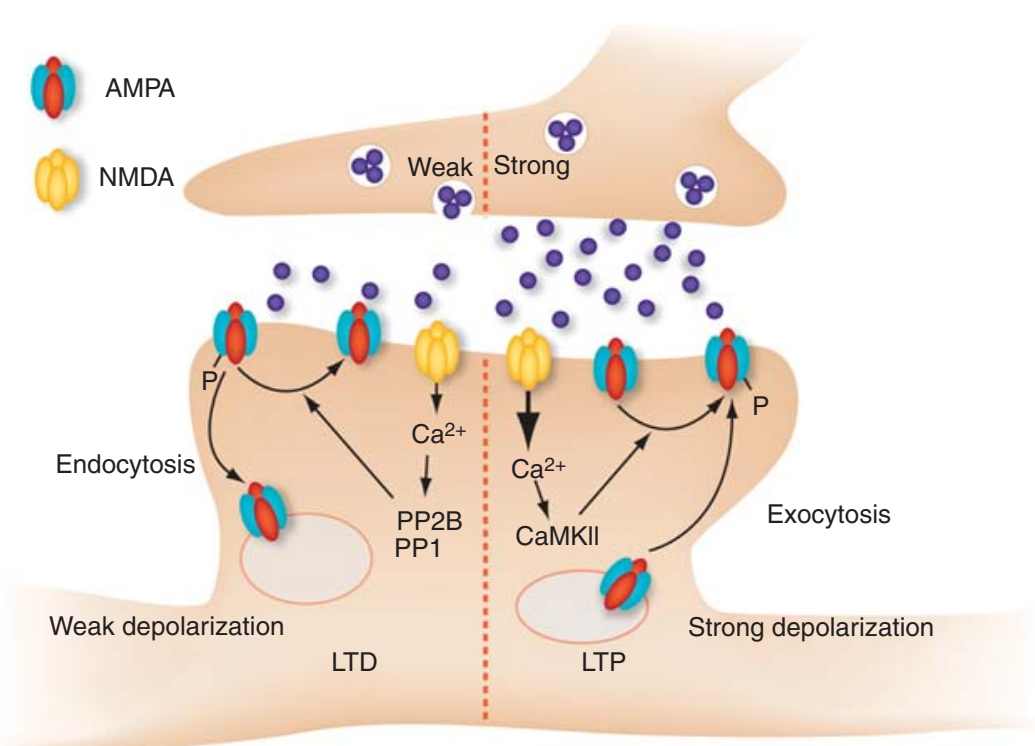

B Blocking LTD by disruption of dynaminamphiphysin interaction (D15 peptide•)

Blocking LTP with tetanus toxin $\bullet$


Figure 3. Postsynaptic expression mechanisms of LTP and LTD. (A) Weak activity of the presynaptic neuron leads to modest depolarization and calcium influx through NMDA receptors. This preferentially activates phosphatases that dephosphorylate AMPA receptors, thus promoting receptor endocytosis. Strong activity paired with strong depolarization triggers LTP in part via CaMKII, receptor phosphorylation, and exocytosis. $(B)$ When endocytosis is blocked with a dynamin dominant-negative peptide, LTD is inhibited. Conversely, blocking exocytosis abolishes LTP. (Left panel: adapted and reprinted, with permission, from Lüscher et al. 1999; right panel: W Morishita and RC Malenka, unpubl.)

is controversial (Adesnik and Nicoll 2007). Of particular interest are members of the TARP family, which interact with all AMPA receptor subunits and control not only membrane insertion but also lateral redistribution (Chen et al. 2000; Tomita et al. 2005; see Blakely and Edwards 2012). If interactions with scaffolding proteins are manipulated through genetic interventions or the perfusion of dominant-negative proteins, LTP and LTD can be blocked (Lüscher et al. 1999; Lüthi et al. 1999; Collingridge and Isaac 2003).

\section{SIGNALING CASCADES FOR TRIGGERING LTP AND LTD}

We have briefly reviewed the mechanisms underlying the induction of LTP and LTD, as well as their expression mechanisms. Appropriate coincident activity of the pre- and postsynaptic 
neurons causes an influx of calcium through NMDARs, and depending on the quantitative characteristics of this calcium signal, AMPARs are either inserted into or removed from the synapses, resulting in LTP or LTD, respectively. But how are the triggering of LTP and LTD and their expression linked? What are the intermediate signaling events that translate the increase in postsynaptic calcium into receptor redistribution? For LTP there is strong evidence that the opening of NMDARs increases calcium concentration sufficiently in the dendritic spine to activate calcium/calmodulin-dependent kinase II (CaMKII), which is found at very high concentrations in spines and which is clearly required for LTP (Lisman et al. 2002). This leads to the phosphorylation of a number of proteins including AMPARs themselves (Derkach et al. 1999). The phosphorylation of AMPAR subunits can cause an increase in the conductance of the AMPAR channel (Benke et al. 1998), another postsynaptic mechanism that contributes to at least the early phase of LTP. In addition, in ways that remain to be determined, the increase in CaMKII activity contributes to the insertion of AMPARs (Ehlers 2000). This can be shown by perfusing the postsynaptic neurons with activated CaMKII, which not only leads to an increase of synaptically evoked currents but also enhances responses to iontophoretically applied AMPA. Importantly, this manipulation occludes further LTP, suggesting a shared mechanism between the ways of increasing synaptic strength (Malenka and Nicoll 1999; Lisman et al. 2002).

Although CaMKII is well accepted to be one major requisite trigger for LTP, like many other cell biological phenomena, the signaling cascades underlying the induction and maintenance (see below) of LTP are extremely complex. A host of additional protein kinases, such as cAMP-dependent protein kinase (PKA), protein kinase $\mathrm{C}(\mathrm{PKC})$, mitogen-activated protein kinases, and tyrosine kinases, have all been suggested to contribute to LTP in various ways (Bliss and Collingridge 1993; Malenka and Nicoll 1999; Salter and Kalia 2004; Sweatt 2004). However, many of the details of their precise function in LTP remain to be worked out.
If LTP involves the activation of CaMKII (and other kinases) and LTD represents the inverse of LTP, then a logical hypothesis is that LTD involves the preferential activation of protein phosphastases. Indeed, a very influential model proposed that NMDAR-dependent LTD depends on the calcium/calmodulin-dependent protein phosphatase calcineurin as well as on protein phosphatase 1 (PP1) (Lisman 1989). This is a very attractive model because calcineurin has a much higher affinity for calcium/calmodulin than does CaMKII and thus will be preferentially activated by a modest increase in calcium, the exact trigger for LTD. There is now strong evidence that these two phosphatases do indeed play a role in LTD (Mulkey et al. 1993, 1994: Carroll et al. 2001), perhaps in part by influencing the phosphorylation state of AMPARs. As was the case for LTP, the intracellular signaling cascades underlying LTD are certainly more complex than simply the activation of two phosphatases. For example, it has been suggested that apoptotic mechanisms including activation of caspase 3 via mitochondria are critical for LTD (Li et al. 2010). Furthermore, the AMPARs that have internalized may need to be degraded via lysosomal or proteasomal pathways so that they are not returned to the plasma membrane.

\section{MAINTENANCE OF LTP AND LTD}

AMPARs are tightly anchored in the PSD by a large number of scaffolding proteins linking them to cytoskeletal elements including actin. Insertion of additional receptors therefore is likely to affect the ultrastructure of the synapse, and in fact, spines associated with synapses that underwent LTP enlarge (Matsuzaki et al. 2004; Harvey and Svoboda 2007; Holtmaat and Svoboda 2009; Kasai et al. 2010). Furthermore, at the ultrastructural level in electron micrographs, synapses that underwent LTP had enlarged PSDs that were often discontinuous (Toni et al. 2001). Such perforated synapses also contain a higher proportion of smooth endoplasmic reticulum and a spine apparatus (Lüscher et al. 2000). A second morphological correlate of LTP besides the physical enlargement 
of spines is the appearance of new spines from the shaft within minutes of the induction protocol (perhaps also by division of an existing spine). Consistent with this idea, the spine density increases following LTP induction, and a significantly higher frequency of multiple-spine synapses (Toni et al. 1999) is observed, as well as a reduction of their turnover (De Roo et al. 2008). Conversely, the triggering of LTD is associated with the shrinkage of dendritic spines and perhaps even their disappearance (Nägerl et al. 2004; Zhou et al. 2004; Wang et al. 2007; Kasai et al. 2010). These observations raise the question of the interdependence of the mechanisms underlying structural and functional plasticity during LTP and LTD, a topic that is being actively investigated.

Not only does long-term plasticity cause structural changes in synapses, but the maintenance of the change in synaptic strength during LTP is protein synthesis-dependent. PKA, CaMKIV, protein kinase $\mathrm{M}-\zeta$, and extracellular signal-regulated kinase (ERK), as well as other signaling molecules, initiate protein synthesis either locally in the dendrites from prefabricated mRNA or by nuclear transcription (Sacktor 2008). The latter involves interactions with transcription factors, including cAMP response element-binding protein (CREB). Both local dendritic and nuclear transcription and somatic translation together are believed to synthesize the proteins required for the maintenance of functional and structural plasticity following the triggering of LTP. In reality, the events of LTP expression and maintenance do not occur sequentially, and the first structural changes, such as the increase of the size of the PSD and spine growth, can be observed rapidly after induction. Through these mechanisms LTP may guide the selective stabilization of synaptic inputs that show coincident activity, whereas nonactivated inputs may be removed and replaced by new spines. Arc is one immediate early gene that may orchestrate the translation of dendritic mRNA required for actin polymerization and stable expansion of dendritic spines during LTP (Bramham et al. 2010). Although such structural changes in spines have been studied in some detail, they are not absolutely required for LTP, as synapses made directly on the dendrites (i.e., shaft synapses) are capable of expressing and maintaining LTP. Moreover, selective interference with the structural changes that accompany LTD do not seem to affect the increase in synaptic strength, at least not in early stages, up to $1-2 \mathrm{hr}$ following induction (Fig. 4) (Wang et al. 2007; Redondo and Morris 2011).

\section{NMDAR-DEPENDENT LTP OF INHIBITORY TRANSMISSION}

Although the vast majority of work on the mechanisms and functions of LTP and LTD have focused on excitatory synapses, potentiation and depression of inhibitory transmission (I-LTP/I-LTD) can also be observed in the brain (Castillo et al. 2011). The underlying molecular mechanisms of I-LTP and I-LTD are variable, but one common feature is that they are often heterosynaptic. Synaptic plasticity of GABAergic

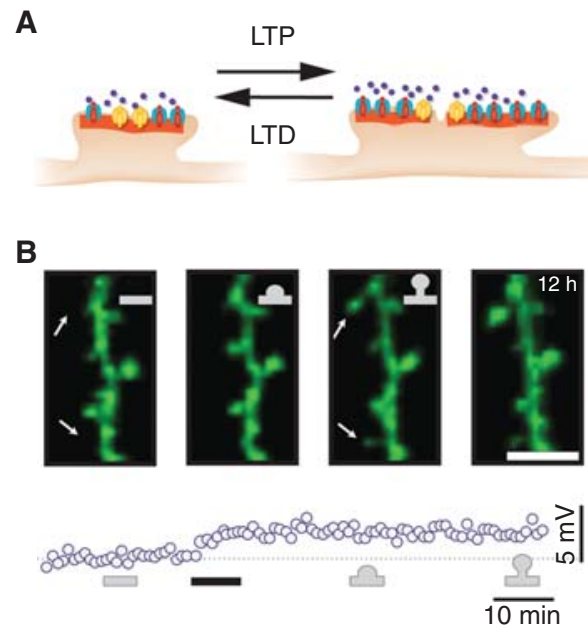

Figure 4. Structural changes associated with LTP and LTD. (A) Synaptic strength correlates with spine volume and the area of the postsynaptic density (orange). Note that the PSD in potentiated synapses is often perforated. (B) LTP can also lead to the appearance of new spines. Within $30 \mathrm{~min}$ of triggering LTP (30 stimuli applied to the presynaptic axon at 10-sec intervals paired with depolarizing current injection into the postsynaptic neuron; black bar) of a synaptic connection in the hippocampus, new spines appear. (Panel created from data adapted from Engert and Bonhoeffer 1999.) 
transmission needs the activation of glutamatergic synapses and a specific messenger that passes the signal from one type of synapses to the other. Here we will focus on the forms of I-LTP/I-LTD that are induced by NMDARs, which, as for the plasticity of excitatory transmission, are classified according to the locus of induction and expression.

In the hippocampus, visual cortex, and optic tectum, a form of I-LTP dependent on brainderived neurotrophic factor (BDNF) has been described (Inagaki et al. 2008). It is induced by activation of NMDARs (and sometimes voltagegated calcium channels) and modulated by $\mathrm{GABA}_{\mathrm{B}}$ receptors, which together drive an increase in cytoplasmic calcium, in part by triggering the release of calcium from intracellular stores. In this model NMDAR activation leads to postsynaptic release of BDNF, which functions as a retrograde messenger and causes an increase in GABA release through activation of presynaptic TrkB receptors.

In the ventral tegmental area, a similar form of plasticity called LTP $_{\mathrm{GABA}}$ is induced by strong activation of NMDARs on dopamine neurons (Nugent et al.2007). This leads to activation of a $\mathrm{Ca}^{2+}$-dependent nitric oxide synthase, which generates nitric oxide, which acts as a retrograde messenger by diffusing back to presynaptic neurons. Nitric oxide in turn causes activation of guanylate cyclase and synthesis of cGMP in the synaptic terminals of inhibitory afferents onto dopamine neurons. The release probability for GABA then increases through a still unknown mechanism involving activation of the cGMPdependent protein kinase, PKG.

The slow $\mathrm{GABA}_{\mathrm{B}}$ receptor-mediated inhibitory postsynaptic potential (IPSP) can also be potentiated if the postsynaptic neuron is strongly depolarized (Huang et al. 2005). The increase of this IPSP also depends on NMDAR activation and CaMKII, thus sharing two key properties with hippocampal LTP of AMPARs.

\section{SYNAPTIC PLASTICITY AND DISEASE}

Altered LTP and LTD has been implicated as a mechanism that may contribute to brain diseases as diverse as dementia, movement disor- ders, depression, addiction, posttraumatic stress syndrome, neuropathic pain, and anxiety disorders. To illustrate this emerging field and to emphasize the point that there are multiple ways by which LTP and LTD can be involved in disease pathophysiology, we will focus on two contrasting conditions: the loss of synaptic plasticity associated with Alzheimer disease's (AD) and excessive plasticity observed after exposure to addictive drugs.

A definitive diagnosis of $\mathrm{AD}$ requires the visualization of amyloid plaques and neurofibrillary tangles in histological sections of the brain. The cognitive decline, however, starts well before this stage, and there is growing evidence that one of the toxic protein species believed to be etiologically related to $\mathrm{AD}$, soluble $\mathrm{A} \beta$ oligomers, causes early memory problems by disrupting LTP and LTD mechanisms (Walsh et al. 2002; Tanzi 2005; Shankar et al. 2008; Cisse et al. 2011). Direct application or overproduction of $A \beta$ oligomers both inhibits LTP and triggers LTD-like changes (Fig. 5). The net result is weaker synapses that have difficulty generating LTP. Furthermore, the toxic A $\beta$ also decreases synaptic NMDARs, a change that contributes to the impaired LTP (Kamenetz et al. 2003). Based on these findings, there is great interest in finding compounds that prevent the synaptic effects of $A \beta$ oligomers with the hope that such compounds will be therapeutically beneficial if given to patients early enough during disease progression. See Sheng et al. (2012) for a comprehensive discussion of synaptic changes associated with AD.

Addictive drugs also have profound effects on synaptic transmission that may influence LTP and LTD (Wolf 2003; Kauer and Malenka 2007; Lüscher and Malenka 2011). For example, a single dose of a drug of abuse such as cocaine enhances excitatory transmission onto dopamine neurons of the ventral tegmental area (Ungless et al. 2001). This drug-evoked plasticity requires activation of type 1 dopamine receptors along with NMDAR activation and is expressed by a redistribution of AMPARs and NMDARs. Calcium-permeable, GluA2-lacking AMPARs appear (Bellone and Lüscher 2006), while NMDAR function is decreased. As a result, 

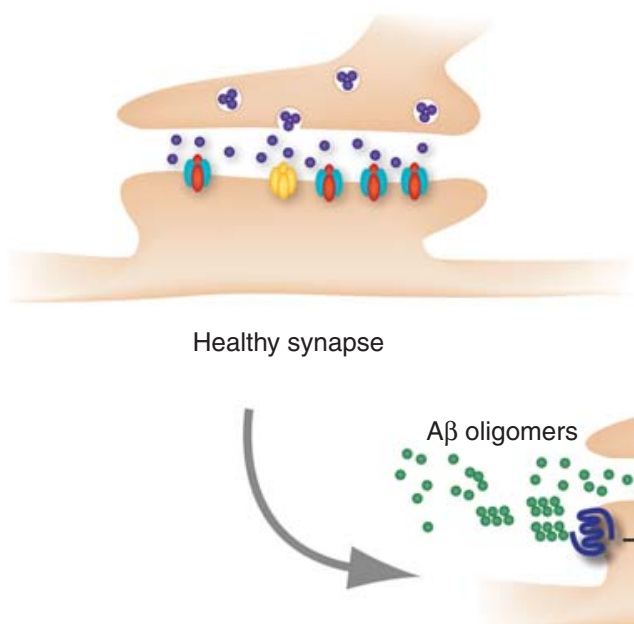

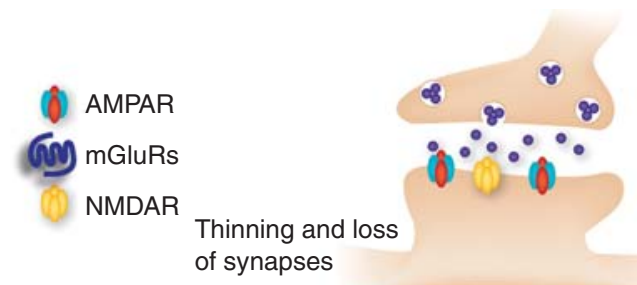

of synapses

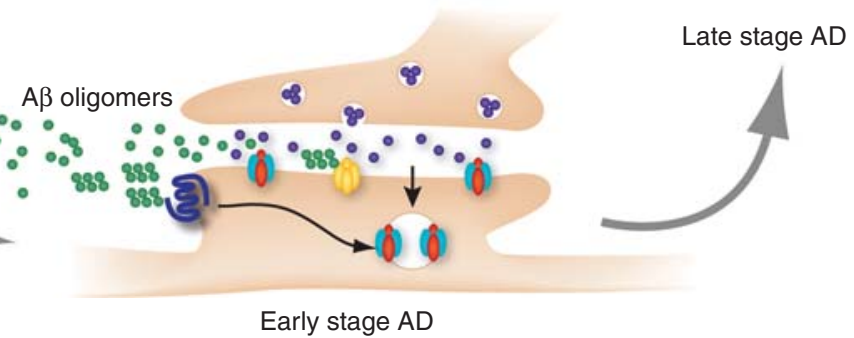

Figure 5. Block of LTP and triggering of LTD by A $\beta$ oligomers in Alzheimer's disease (AD). Soluble A $\beta$ oligomers strongly activate metabotropic glutamate receptors (mGluRs), which leads to the internalization of AMPARs and LTD. As a consequence, normal NMDAR-dependent LTD is occluded. At the same time they inhibit NMDARs, precluding the induction of LTP. In a second step synapses become thinner and some disappear. It is believed that these changes underlie the early cognitive decline observed in AD.

the primary source for synaptic calcium entry shifts from NMDARs in naïve animals to GluA2-lacking AMPARs after a dose of an addictive drug. As a consequence, the rules for subsequent activity-dependent plasticity are inverted (Mameli and Lüscher 2011). These early drug-evoked changes in the properties of excitatory synapses on dopamine cells can be very long-lasting and are followed by many additional synaptic modifications in related structures. For example, in the nucleus accumbens chronic (5-d) administration of cocaine triggers an internalization of AMPARs in medium spiny neurons, a change that occludes the subsequent synaptic induction of NMDARdependent LTD (Thomas and Malenka 2003; Kauer and Malenka 2007; Wolf and Ferrario 2010).

\section{CONCLUSIONS}

Because of a major effort by a large number of investigators, the mechanisms underlying NMDAR-dependent LTP and LTD are understood in reasonable molecular detail. Coinci- dent activity in pre- and postsynaptic neurons resulting in calcium influx through synaptic NMDARs is well established to be necessary for the triggering of both LTP and LTD. This causes the activity-dependent redistribution of AMPARs, a general mechanism for modifying synaptic strength in many neuronal cell types. Elucidating the detailed molecular mechanisms by which AMPARs traffic to and away from synapses is an active topic of current investigations (see West and Greenberg 2012). An equally important topic is the identification of the proteins that need to be synthesized to maintain LTP and LTD. Through coordination of functional changes in synaptic efficacy to structural changes in synapses, the reorganization of neural networks can be structurally maintained for long periods of time. Certainly, more complete understanding of the mechanisms underlying LTP and LTD will continue to contribute to our understanding of the mechanisms of learning and memory (see Mayford et al. 2012), as well as provide insight into the pathophysiology of a broad spectrum of brain diseases (see Sheng et al. 2012). 


\section{REFERENCES}

* Reference is also in this collection.

Adesnik H, Nicoll RA. 2007. Conservation of glutamate receptor 2-containing AMPA receptors during longterm potentiation. J Neurosci 27: 4598-4602.

Arancio O, Kiebler M, Lee CJ, Lev-Ram V, Tsien RY, Kandel ER, Hawkins RD. 1996. Nitric oxide acts directly in the presynaptic neuron to produce long-term potentiation in cultured hippocampal neurons. Cell 87: 1025-1035.

Bellone C, Lüscher C. 2006. Cocaine triggered AMPA receptor redistribution is reversed in vivo by mGluR-dependent long-term depression. Nat Neurosci 9: 636-641.

Benke TA, Lüthi A, Isaac JT, Collingridge GL. 1998. Modulation of AMPA receptor unitary conductance by synaptic activity. Nature 393: 793-797.

Bienenstock EL, Cooper LN, Munro PW. 1982. Theory for the development of neuron selectivity: Orientation specificity and binocular interaction in visual cortex. $\mathrm{J} \mathrm{Neu}$ rosci 2: $32-48$.

* Blakely RD, Edwards RH. 2012. Vesicular and plasma membrane transporters for neurotransmitters. Cold Spring Harb Perspect Biol doi: 10.1101/cshperspect.a005595.

Bliss TV, Collingridge GL. 1993. A synaptic model of memory: Long-term potentiation in the hippocampus. Nature 361: 31-39.

Bloodgood BL, Sabatini BL. 2007. Nonlinear regulation of unitary synaptic signals by $\mathrm{CaV}_{2.3}$ voltage-sensitive calcium channels located in dendritic spines. Neuron 53: 249-260.

Bloodgood BL, Giessel AJ, Sabatini BL. 2009. Biphasic synaptic Ca influx arising from compartmentalized electrical signals in dendritic spines. PLoS Biol 7: e1000190.

Bramham CR, Alme MN, Bittins M, Kuipers SD, Nair RR, Pai B, Panja D, Schubert M, Soule J, Tiron A, et al. 2010. The Arc of synaptic memory. Exp Brain Res 200: 125140.

Caporale N, Dan Y. 2008. Spike timing-dependent plasticity: A Hebbian learning rule. Annu Rev Neurosci 31: 25-46.

Carroll RC, Beattie EC, von Zastrow M, Malenka RC. 2001. Role of AMPA receptor endocytosis in synaptic plasticity. Nat Rev Neurosci 2: 315-324.

* Castillo PE. 2012. Presynaptic LTP and LTD of excitatory and inhibitory synapses. Cold Spring Harb Perspect Biol doi: 10.1101/cshperspect.a005728.

Castillo PE, Chiu CQ, Carroll RC. 2011. Long-term plasticity at inhibitory synapses. Curr Opin Neurobiol 21: $328-338$.

Chen L, Chetkovich DM, Petralia RS, Sweeney NT, Kawasaki Y, Wenthold RJ, Bredt DS, Nicoll RA. 2000. Stargazin regulates synaptic targeting of AMPA receptors by two distinct mechanisms. Nature 408: 936-943.

Cisse M, Halabisky B, Harris J, Devidze N, Dubal DB, Sun B, Orr A, Lotz G, Kim DH, Hamto P, et al. 2011. Reversing EphB2 depletion rescues cognitive functions in Alzheimer model. Nature 469: 47-52.

Collingridge GL, Isaac JT. 2003. Functional roles of protein interactions with AMPA and kainate receptors. Neurosci Res 47: 3-15.
Collingridge GL, Isaac JT, Wang YT. 2004. Receptor trafficking and synaptic plasticity. Nat Rev Neurosci 5: 952-962.

Dan Y, Poo MM. 2006. Spike timing-dependent plasticity: From synapse to perception. Physiol Rev 86: 1033-1048.

De Roo M, Klauser P, Muller D. 2008. LTP promotes a selective long-term stabilization and clustering of dendritic spines. PLoS Biol 6: e219.

Derkach V, Barria A, Soderling TR. 1999. $\mathrm{Ca}^{2+} /$ calmodulinkinase II enhances channel conductance of $\alpha$-amino3-hydroxy-5-methyl-4-isoxazolepropionate type glutamate receptors. Proc Natl Acad Sci 96: 3269-3274.

Diamond JS, Bergles DE, Jahr CE. 1998. Glutamate release monitored with astrocyte transporter currents during LTP. Neuron 21: 425-433.

Dingledine R, Borges K, Bowie D, Traynelis SF. 1999. The glutamate receptor ion channels. Pharmacol Rev 51: 7-61.

Ehlers MD. 2000. Reinsertion or degradation of AMPA receptors determined by activity-dependent endocytic sorting. Neuron 28: 511-525.

Elias GM, Nicoll RA. 2007. Synaptic trafficking of glutamate receptors by MAGUK scaffolding proteins. Trends Cell Biol 17: 343-352.

Engert F, Bonhoeffer T. 1997. Synapse specificity of longterm potentiation breaks down at short distances. Nature 388: $279-284$.

Harvey CD, Svoboda K. 2007. Locally dynamic synaptic learning rules in pyramidal neuron dendrites. Nature 450: $1195-1200$.

Harvey CD, Yasuda R, Zhong H, Svoboda K. 2008. The spread of Ras activity triggered by activation of a single dendritic spine. Science 321: 136-140.

Hebb DO. 1949. The organization of behavior: A neuropsychological theory. John Wiley \& Sons, New York.

Holtmaat A, Svoboda K. 2009. Experience-dependent structural synaptic plasticity in the mammalian brain. Nat Rev Neurosci 10: 647-658

Huang CS, Shi SH, Ule J, Ruggiu M, Barker LA, Darnell RB, Jan YN, Jan LY. 2005. Common molecular pathways mediate long-term potentiation of synaptic excitation and slow synaptic inhibition. Cell 123: 105-118.

Inagaki T, Begum T, Reza F, Horibe S, Inaba M, Yoshimura Y, Komatsu Y. 2008. Brain-derived neurotrophic factor-mediated retrograde signaling required for the induction of long-term potentiation at inhibitory synapses of visual cortical pyramidal neurons. Neurosci Res 61: 192-200.

Isaac JTR, Nicoll RA, Malenka RC. 1995. Evidence for silent synapses. Implications for the expression of LTP. Neuron 15: $427-434$.

Jahr CE, Stevens CF. 1993. Calcium permeability of the $N$ methyl-D-aspartate receptor channel in hippocampal neurons in culture. Proc Natl Acad Sci 90: 11573-11577.

Kamenetz F, Tomita T, Hsieh H, Seabrook G, Borchelt D, Iwatsubo T, Sisodia S, Malinow R. 2003. APP processing and synaptic function. Neuron 37: 925-937.

Kasai H, Fukuda M, Watanabe S, Hayashi-Takagi A, Noguchi J. 2010. Structural dynamics of dendritic spines in memory and cognition. Trends Neurosci 33: 121-129.

Kauer JA, Malenka RC. 2007. Synaptic plasticity and addiction. Nat Rev Neurosci 8: 844-858. 
Kennedy MJ, Ehlers MD. 2011. Mechanisms and function of dendritic exocytosis. Neuron 69: 856-875.

Li Z, Jo J, Jia JM, Lo SC, Whitcomb DJ, Jiao S, Cho K, Sheng M. 2010. Caspase-3 activation via mitochondria is required for long-term depression and AMPA receptor internalization. Cell 141: 859-871.

Liao DZ, Hessler NA, Malinow R. 1995. Activation of postsynaptically silent synapses during pairing induced LTP in CA1 region of hippocampal slice. Nature 375: 400404.

Lisman J. 1989. A mechanism for the Hebb and the antiHebb processes underlying learning and memory. Proc Natl Acad Sci 86: 9574-9578.

Lisman J, Schulman H, Cline H. 2002. The molecular basis of CaMKII function in synaptic and behavioural memory. Nat Rev Neurosci 3: 175-190.

Liu SJ, Zukin RS. 2007. $\mathrm{Ca}^{2+}$-permeable AMPA receptors in synaptic plasticity and neuronal death. Trends Neurosci 30: $126-134$.

Lledo PM, Zhang X, Sudhof TC, Malenka RC, Nicoll RA. 1998. Postsynaptic membrane fusion and long-term potentiation. Science 279: 399-403.

Lüscher C, Frerking M. 2001. Restless AMPA receptors: Implications for synaptic transmission and plasticity. Trends Neurosci 24: 665-670.

Lüscher C, Malenka RC. 2011. Drug-evoked synaptic plasticity in addiction: From molecular changes to circuit remodeling. Neuron 69: 650-663.

Lüscher C, Malenka RC, Nicoll RA. 1998. Monitoring glutamate release during LTP with glial transporter currents. Neuron 21: 435-441.

Lüscher C, Xia H, Beattie EC, Carroll RC, von Zastrow M, Malenka RC, Nicoll RA. 1999. Role of AMPA receptor cycling in synaptic transmission and plasticity. Neuron 24: 649-658.

Lüscher C, Nicoll RA, Malenka RC, Muller D. 2000. Synaptic plasticity and dynamic modulation of the postsynaptic membrane. Nat Neurosci 3: 545-550.

Lüthi A, Chittajallu R, Duprat F, Palmer MJ, Benke TA, Kidd FL, Henley JM, Isaac JT, Collingridge GL. 1999. Hippocampal LTD expression involves a pool of AMPARs regulated by the NSF-GluR2 interaction. Neuron 24: 389-399.

Malenka RC. 1994. Synaptic plasticity in the hippocampus: LTP and LTD. Cell 78: 535-538.

Malenka RC, Bear MF. 2004. LTP and LTD: An embarrassment of riches. Neuron 44: 5-21.

Malenka RC, Nicoll RA. 1999. Long-term potentiation-a decade of progress? Science 285: 1870-1874.

Malinow R, Malenka RC. 2002. AMPA receptor trafficking and synaptic plasticity. Annu Rev Neurosci 25: 103-126.

Mameli M, Lüscher C. 2011. Synaptic plasticity and addiction: Learning mechanisms gone awry. Neuropharmacology 61: 1052-1059.

Manabe T, Nicoll RA. 1994. Long-term potentiation: Evidence against an increase in transmitter release probability in the CA1 region of the hippocampus. Science 265: $1888-1892$.

Manabe T, Wyllie DJ, Perkel DJ, Nicoll RA. 1993. Modulation of synaptic transmission and long-term poten- tiation: Effects on paired pulse facilitation and EPSC variance in the CA1 region of the hippocampus. J Neurophysiol 70: 1451-1459.

Matsuzaki M, Honkura N, Ellis-Davies GC, Kasai H. 2004. Structural basis of long-term potentiation in single dendritic spines. Nature 429: 761-766.

* Mayford M, Siegelbaum SA, Kandel ER. 2012. Synapses and memory storage. Cold Spring Harb Perspect Biol doi: 10.1101/cshperspect.a005751.

McNaughton BL. 1982. Long-term synaptic enhancement and short-term potentiation in rat fascia dentata act through different mechanisms. J Physiol 324: 249-262.

Mulkey RM, Herron CE, Malenka RC. 1993. An essential role for protein phosphatases in hippocampal long-term depression. Science 261: 1051-1055.

Mulkey RM, Endo S, Shenolikar S, Malenka RC. 1994. Involvement of a calcineurin/inhibitor-1 phosphatase cascade in hippocampal long-term depression. Nature 369: 486-488.

Nägerl UV, Eberhorn N, Cambridge SB, Bonhoeffer T. 2004. Bidirectional activity-dependent morphological plasticity in hippocampal neurons. Neuron 44: 759-767.

Nicoll RA. 2003. Expression mechanisms underlying longterm potentiation: A postsynaptic view. Philos Trans R Soc Lond B Biol Sci 358: 721-726.

Nugent FS, Penick EC, Kauer JA. 2007. Opioids block longterm potentiation of inhibitory synapses. Nature 446: 1086-1090.

Plant K, Pelkey KA, Bortolotto ZA, Morita D, Terashima A, McBain CJ, Collingridge GL, Isaac JT. 2006. Transient incorporation of native GluR2-lacking AMPA receptors during hippocampal long-term potentiation. Nat Neurosci 9: 602-604.

Redondo RL, Morris RG. 2011. Making memories last: The synaptic tagging and capture hypothesis. Nat Rev Neurosci 12: 17-30.

Sabatini BL, Oertner TG, Svoboda K. 2002. The life cycle of $\mathrm{Ca}^{2+}$ ions in dendritic spines. Neuron 33: 439-452.

Sacktor TC. 2008. PKM $\zeta$, LTP maintenance, and the dynamic molecular biology of memory storage. Prog Brain Res 169: $27-40$.

Salter MW, Kalia LV. 2004. Src kinases: A hub for NMDA receptor regulation. Nat Rev Neurosci 5: 317-328.

Schulz PE, Cook EP, Johnston D. 1995. Using paired-pulse facilitation to probe the mechanisms for long-term potentiation (LTP). J Physiol Paris 89: 3-9.

Shankar GM, Li S, Mehta TH, Garcia-Munoz A, Shepardson NE, Smith I, Brett FM, Farrell MA, Rowan MJ, Lemere CA, et al. 2008. Amyloid- $\beta$ protein dimers isolated directly from Alzheimer's brains impair synaptic plasticity and memory. Nat Med 14: 837-842.

* Sheng M, Kim E. 2012. The postsynaptic organization of synapses. Cold Spring Harb Perspect Biol doi: 10.1101/ cshperspect.a005678.

* Sheng M, Sabatini B, Südhof TC. 2012. Synapses and Alzheimer's disease. Cold Spring Harb Perspect Biol doi: 10.1101/cshperspect.a005777.

Stuart G, Spruston N, Sakmann B, Hausser M. 1997. Action potential initiation and backpropagation in neurons of the mammalian CNS. Trends Neurosci 20: 125-131. 
NMDA Receptor-Dependent LTP/LTD

Sweatt JD. 2004. Mitogen-activated protein kinases in synaptic plasticity and memory. Curr Opin Neurobiol 14: 311-317.

Tanzi RE. 2005. The synaptic $A \beta$ hypothesis of Alzheimer disease. Nat Neurosci 8: 977-979.

Thomas MJ, Malenka RC. 2003. Synaptic plasticity in the mesolimbic dopamine system. Philos Trans R Soc Lond B Biol Sci 358: 815-819.

Tomita S, Stein V, Stocker TJ, Nicoll RA, Bredt DS. 2005 Bidirectional synaptic plasticity regulated by phosphorylation of stargazin-like TARPs. Neuron 45: 269-277.

Toni N, Buchs PA, Nikonenko I, Bron CR, Muller D. 1999. LTP promotes formation of multiple spine synapses between a single axon terminal and a dendrite. Nature $\mathbf{4 0 2}$ 421-425.

Toni N, Buchs PA, Nikonenko I, Povilaitite P, Parisi L, Muller D. 2001. Remodeling of synaptic membranes after induction of long-term potentiation. J Neurosci 21: 62456251.

Ungless MA, Whistler JL, Malenka RC, Bonci A. 2001. Single cocaine exposure in vivo induces long-term potentiation in dopamine neurons. Nature 411: 583-587.

Walsh DM, Klyubin I, Fadeeva JV, Cullen WK, Anwyl R, Wolfe MS, Rowan MJ, Selkoe DJ. 2002. Naturally secreted oligomers of amyloid $\beta$ protein potently inhibit hippocampal long-term potentiation in vivo. Nature 416: 535-539.
Wang XB, Yang Y, Zhou Q. 2007. Independent expression of synaptic and morphological plasticity associated with long-term depression. J Neurosci 27: 12419-12429.

Waters J, Schaefer A, Sakmann B. 2005. Backpropagating action potentials in neurones: Measurement, mechanisms and potential functions. Prog Biophys Mol Biol 87: $145-170$.

* West AE, Greenberg ME. 2012. Neuronal activity-regulated gene transcription in synapse development and cognitive function. Cold Spring Harb Perspect Biol doi: 10.1101/ cshperspect.a005744.

Williams JH, Li YG, Nayak A, Errington ML, Murphy KP, Bliss TV. 1993. The suppression of long-term potentiation in rat hippocampus by inhibitors of nitric oxide synthase is temperature and age dependent. Neuron 11: $877-884$.

Wolf ME. 2003. LTP may trigger addiction. Mol Interv 3: $248-252$.

Wolf ME, Ferrario CR. 2010. AMPA receptor plasticity in the nucleus accumbens after repeated exposure to cocaine. Neurosci Biobehav Rev 35: 185-211.

Zakharenko SS, Zablow L, Siegelbaum SA. 2001. Visualization of changes in presynaptic function during long-term synaptic plasticity. Nat Neurosci 4: 711-717.

Zhou Q, Homma KJ, Poo MM. 2004. Shrinkage of dendritic spines associated with long-term depression of hippocampal synapses. Neuron 44: 749-757. 


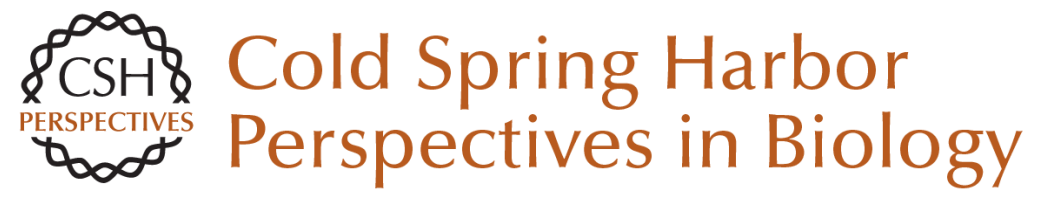

\section{NMDA Receptor-Dependent Long-Term Potentiation and Long-Term Depression (LTP/LTD)}

Christian Lüscher and Robert C. Malenka

Cold Spring Harb Perspect Biol 2012; doi: 10.1101/cshperspect.a005710 originally published online April 17,2012

\section{Subject Collection The Synapse}

\section{Studying Signal Transduction in Single Dendritic \\ Spines \\ Ryohei Yasuda}

Synaptic Vesicle Pools and Dynamics

AbdulRasheed A. Alabi and Richard W. Tsien

Synapses and Memory Storage

Mark Mayford, Steven A. Siegelbaum and Eric R. Kandel

\section{Synapses and Alzheimer's Disease}

Morgan Sheng, Bernardo L. Sabatini and Thomas C. Südhof

Synaptic Cell Adhesion

Markus Missler, Thomas C. Südhof and Thomas Biederer

Synaptic Dysfunction in Neurodevelopmental

Disorders Associated with Autism and Intellectual

Disabilities

Huda Y. Zoghbi and Mark F. Bear

The Postsynaptic Organization of Synapses Morgan Sheng and Eunjoon Kim

Presynaptic LTP and LTD of Excitatory and Inhibitory Synapses

Pablo E. Castillo
Synaptic Vesicle Endocytosis

Yasunori Saheki and Pietro De Camilli

Short-Term Presynaptic Plasticity Wade G. Regehr

NMDA Receptor-Dependent Long-Term

Potentiation and Long-Term Depression

(LTP/LTD)

Christian Lüscher and Robert C. Malenka

Ultrastructure of Synapses in the Mammalian

Brain

Kristen M. Harris and Richard J. Weinberg

Calcium Signaling in Dendritic Spines

Michael J. Higley and Bernardo L. Sabatini

Synaptic Neurotransmitter-Gated Receptors

Trevor G. Smart and Pierre Paoletti

\section{Synaptic Vesicle Exocytosis}

Thomas C. Südhof and Josep Rizo

Vesicular and Plasma Membrane Transporters for Neurotransmitters

Randy D. Blakely and Robert H. Edwards

For additional articles in this collection, see http://cshperspectives.cshlp.org/cgi/collection/

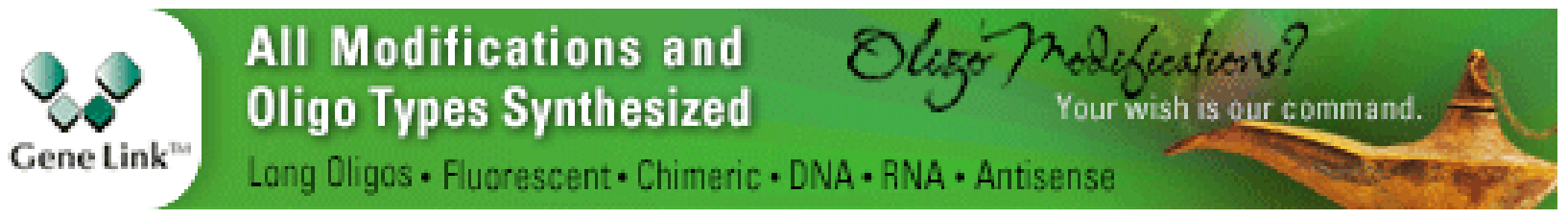

Copyright @ 2012 Cold Spring Harbor Laboratory Press; all rights reserved 